FEATURE

Alex Turvey

Office for National Statistics

\title{
Developing a unit labour costs indicator for the
} UK

\section{Introduction}

\section{SUMMARY}

This article showcases ongoing work within ONS to develop a new unit labour costs indicator for the UK by building upon the existing unit wage costs series. It begins by examining the concept of unit wage costs, describing what the series aims to measure and explaining some of the conceptual difficulties when estimating data in practice. The first issue concerns the series used to measure the labour costs of employees; wages and salaries are currently used instead of the more comprehensive compensation of employees (COE) series. Secondly, the labour costs of the self-employed are not satisfactorily estimated by the current method. Two possible methods for the development of a unit labour costs measure are outlined; both incorporate $\mathrm{COE}$ as their employee labour costs measure, but take different approaches to estimating the labour costs of the self-employed. The article concludes that the preferred model for estimating unit labour costs proxies self-employed labour costs by applying the ratio of COE to the sum of $\mathrm{CoE}$ and gross operating surplus in the employed sector to mixed income, a measure of total earnings in the selfemployed sector. r he Office for National Statistics (ONS) publishes estimates of unit wage costs on a quarterly basis, as part of the Productivity Statistical Bulletin (until now called the Productivity First Release). The purpose of the unit wage costs series is to measure the labour costs incurred to produce one unit of output. In principle, it aims to capture how much firms pay in wages, social security contributions and other benefits in kind per unit of final output produced. Although not a direct measure of productivity, since productivity relates the volume of output to the volume of input used to produce that output, an inverse relationship between unit wage costs and productivity series tends to be observed - the higher the productivity of a worker, the lower the cost of labour per unit of output, and vice versa.

This article reviews the current methodology used to construct the unit wage cost series, outlining two limitations which should be addressed, relating to the measure of labour remuneration used and the returns to self-employed labour, and proposes two methodologies to incorporate better estimates of self-employed labour costs to produce a more consistent and comprehensive series. The article concludes by recommending a preferred methodology for the compilation of a new unit labour costs measure.

Measurement of unit wage costs Unit wage costs are currently calculated as a ratio of total wages and salaries (W\&S) per employee to Gross Value Added (GVA) per worker, as outlined in the Background
Notes of the Productivity Statistical Bulletin/First Release.

Unit Wage Costs = $\frac{\text { Wages and Salaries }}{\text { LFS Employees }} / \frac{\text { GVA at basic prices }}{\text { LFS Employment }}$

The limitations in the construction of unit wage costs are:

1. The use of W\&S instead of compensation of employees ( $\mathrm{CoE})$ to measure employee labour costs

2. The treatment of labour costs for selfemployed workers

\section{The choice of measure for employee labour costs}

The measure of labour costs currently used is W\&S rather than CoE. According to the National Accounts Concepts, Sources and Methods Manual, compensation of employees is defined as the total remuneration payable by enterprises in cash or in kind. While this is predominantly made up of wages and salaries (approximately 85 per cent), it does include additional components not covered by W\&S, such as employer pension contributions, social security payments and benefits in kind.

To give an idea of how the adoption of $\mathrm{CoE}$ as the numerator of a unit labour costs indicator might affect the existing series, Figure 1 presents whole economy growth rates of CoE and W\&S since 2001. Over this period, the patterns of growth of the two series are clearly different; growth in $\mathrm{CoE}$ tended to be higher between 2002 and 2006 


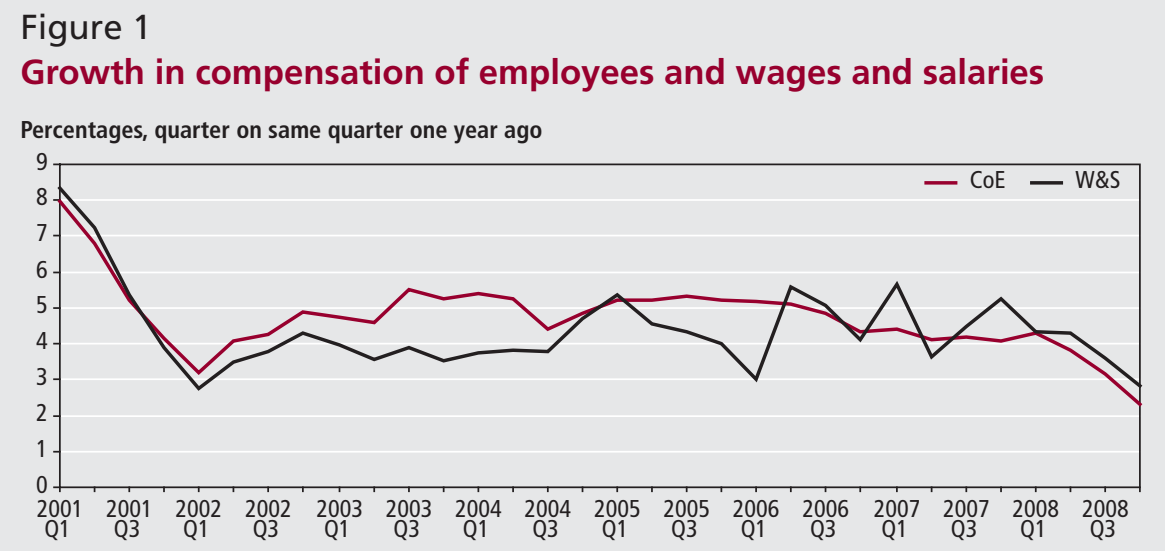

Source: National Accounts, Office for National Statistics

before dipping below that of W\&S, and was less volatile throughout the time series. This suggests that the change in numerator could have a smoothing effect on published figures.

But the main argument for the inclusion of $\mathrm{CoE}$ is a conceptual one: pension contributions, social security and other benefits represent around 15 per cent of the cost of employing labour and their inclusion would provide a more complete picture of cost pressures per unit of output. Thus, it is recommended by this article that $\mathrm{CoE}$ be applied in the calculation of unit labour costs. This recommendation is in line with the guidance laid out in the OECD Productivity Manual (2001).

\section{Estimating self-employed labour costs}

The second conceptual limitation of the current unit wage costs series concerns the estimation of the labour costs of the self-employed. There is no direct measure of labour costs in the self-employed sector because the self-employed do not remunerate themselves specifically for their labour input, but for a service which also includes capital input embodied in their entrepreneurial effort. The combined returns to their labour and capital inputs are captured in the 'mixed income' series in the National Accounts.

The self-employed represent 13 per cent of total employment, as classified in the Labour Force Survey (LFS), with 86 per cent classed as employees and the remainder made up of HM forces, Governmentsupported trainees (GSTs) and unpaid family workers. With the self-employed making up such a significant proportion of the workforce, it is important that any unit wage cost indicator quantifies the labour costs of the self-employed as accurately as possible, based on the most appropriate method of estimation.

Under the current unit wage costs methodology, labour costs of the self- employed are estimated by scaling up W\&S by multiplying it by the ratio of all persons in employment to all employees (the majority of the difference between the two being the self-employed). Rearranging equation (1):

\section{Unit Wage Costs = \\ $\frac{\text { Wages and Salaries }}{\text { LFS Employees }} \times \frac{\text { LFS Employment }}{\text { GVA at basic prices }}$}

Unit Wage Costs =

Wages and Salaries $\times \frac{\text { LFS Employment }}{\text { LFS Employees }}$

GVA

The key assumption of this method is that the 'average wage', or average absolute labour cost, of the self-employed is the same as the average wage for employees. This is unlikely to be the case for several reasons:

- The distribution of hours worked differs from that for employees. According to table 7(1) of the Labour Market Statistics Statistical Bulletin/First Release, a far higher proportion of the self-employed usually work over 45 hours ( 31 per cent in the first quarter of 2009) compared with employees (18 per cent), which is offset by a smaller proportion working between 31 and 45 hours. This implies the average labour input (in volume terms) is greater for the self-employed

- The self-employed are generally more flexible in their working practices, tending to vary their hours and methods of work to a greater extent than employees, and taking fewer holidays

- Compared to employees, the self-employed are more strongly represented in certain industries, and less common in others. For example, a far greater proportion work in construction and agriculture, while a much smaller proportion work in public administration, health and education. Given the significant variation in average hours worked and labour compensation that exists across industrial sectors, the differing industries in which employees and the self-employed work is likely to drive differences in their average labour costs

But most significantly, evidence from the National Accounts and the LFS shows the self-employed do earn less than the employed - a measure of average wages (W\&S divided by total employees) persistently exceeds mixed income (which measures returns to both labour and capital) divided by total self-employment. This is demonstrated using annual data for 2000-08 in Table 1. So even in the extreme case of the returns to labour accounting for all of mixed income, average labour costs for the self-employed are still lower than those of employees. By extension, this means that the implied return to selfemployed labour in equation (2):

Wages and Salaries $\times \frac{\text { LFS self-employment }}{\text { LFS employees }}$

must be greater than total mixed income, which is not plausible. This issue will be revisited later in the article in the discussion of the two proposed models for estimating unit labour costs.

One possible explanation for this finding may lie in the self-employed under-reporting their earnings to $\mathrm{HM}$ Revenue and Customs in order to lower their tax liability. ONS recognises this potential downward bias in self-employed income reporting and applies an upward adjustment to compensate, but it is possible that this adjustment is not sufficient and it is difficult to assess whether this is the case. Consequently, it is clear that the assumption of equal average labour income in the employed and self-employed sectors may not be realistic.

A further problem with the current unit wage cost construction is that the scaling ratio of employment to employees results in the double-counting of HM forces and GSTs. The difference between employment and employees includes HM forces and GSTs as well as the self-employed, but their earnings are already captured in W\&S (and CoE). Hence, the equation is estimating the labour costs of some people whose wages are already being measured in the W\&S series. This error may be small, given the relative size of HM forces and GSTs in total employment, but it nevertheless should be corrected.

\section{Proposed models for the} estimation of unit labour costs

The rest of this article compares two possible models to estimate unit labour 
Table 1 Estimates of average labour compensation for employees and the
self-employed

f mixed income per self-employed person wages and salaries per employee

\begin{tabular}{lrr} 
& mixed income per self-employed person & wages and salaries per employee \\
\hline 2000 & 17485 & 19285 \\
2001 & 18593 & 20303 \\
2002 & 19469 & 20857 \\
2003 & 19165 & 21600 \\
2004 & 20126 & 22292 \\
2005 & 20588 & 23047 \\
2006 & 21110 & 23914 \\
2007 & 21969 & 24942 \\
2008 & 22392 & 25669 \\
\hline
\end{tabular}

Source: Labour Force Survey and National Accounts, Office for National Statistics

costs. Both are based on CoE rather than W\&S, in line with the main recommendation of this article described earlier. The two models differ in the way self-employed labour costs are estimated. This section therefore focuses on how each method proxies the labour costs of the selfemployed.

Model 1: Adjust CoE to include the self-employed using the ratio of hours worked by all in employment to hours worked by all employees This method is very similar to the existing unit wage costs methodology, but the 'scaling factor' is based on a ratio of hours rather than workers:

Unit Labour Costs =

LFS hours worked

CoE $\times \frac{\text { by all in employment }}{\text { LFS hours worked }}$

by all employees

$$
\text { GVA }
$$

This model differs from the current unit wage costs construction in that it assumes equivalent average hourly, rather than absolute, returns to labour in the employed and self-employed sectors. It therefore overcomes the inconsistency in the published series arising from the differing working hours of the employed and self-employed. The method is also recommended by the OECD (2008), which describes the numerator of equation (3) as the 'target variable' for total labour costs.

However, it doesn't overcome the assumption that the average return to labour in the employed sector is the same as that in the self-employed sector. As a result, the implied return to self-employed labour:

LFS hours worked by

CoE $\times \frac{\text { all self-employed persons }}{\text { LFS hours worked by }}$ all employees

persistently exceeds mixed income (which is a measure of returns to both labour and capital) - an implausible result. This is shown for annual data between 2000 and 2008 in Table 2. Given that hours worked by the self-employed as a proportion of total hours worked is greater than selfemployment as a proportion of total employment, the estimate of self-employed labour costs, and hence the discrepancy with mixed income, is in fact greater than under the current construction.

Model 2: Infer self-employed labour costs from mixed income using the ratio of $\mathrm{COE}$ to the sum of $\mathrm{COE}$ and GOS in the employed sector Gross domestic product (GDP) can be measured from an income approach, where total income in the UK economy is the sum of compensation of employees, gross operating surplus and mixed income. $\mathrm{CoE}$ and GOS measure the returns to employed labour and capital, respectively, while mixed income captures the returns to both labour and capital for the selfemployed. The basis of this model is to assume that the relative returns to labour and capital are the same for the selfemployed as for the employed. This ratio can then be applied to the mixed income component to split out returns to capital and labour for the self-employed.

$\mathrm{CoE}+$ Mixed Income + GOS

$=\mathrm{GDP}(\mathrm{I})$

$\frac{\mathrm{CoE}}{\mathrm{CoE}+\mathrm{GOS}} \times$ Mixed Income

$=$ Return to self-employed labour

Hence, $\frac{\text { GOS }}{\mathrm{CoE}+\mathrm{GOS}} \times$ Mixed Income

$=$ Return to capital for the self-employed (6)

Note that by definition,

$\frac{\mathrm{CoE}}{\mathrm{CoE}+\mathrm{GOS}}+\frac{\mathrm{GOS}}{\mathrm{CoE}+\mathrm{GOS}}=1$
Equivalently, (5) can be written as:

$$
\frac{\text { Mixed Income }}{\mathrm{CoE}+\mathrm{GOS}} \times \mathrm{CoE}
$$

Hence, unit labour costs $=$

$$
\frac{\mathrm{CoE}+\left(\mathrm{CoE} \times \frac{\mathrm{MI}}{\mathrm{CoE}+\mathrm{GOS}}\right)}{\mathrm{GVA}}
$$$$
=\frac{\operatorname{CoE}\left(1+\frac{\mathrm{MI}}{\mathrm{CoE}+\mathrm{GOS}}\right)}{\mathrm{GVA}}
$$

$$
=\frac{\mathrm{CoE}\left(\frac{\mathrm{CoE}+\mathrm{GOS}+\mathrm{MI}}{\mathrm{CoE}+\mathrm{GOS}}\right)}{\mathrm{GVA}}
$$

$=\frac{\operatorname{CoE}\left(\frac{\mathrm{GDP}(\mathrm{I})}{\mathrm{CoE}+\mathrm{GOS}}\right)}{\mathrm{GVA}}$

Therefore, the 'scaling factor' used to proxy self-employed labour costs under this method is the ratio of total income to the sum of $\mathrm{CoE}$ and GOS.

The crucial difference between this model and the other series lies in the assumption that the labour costs of the self-employed are equivalent to those of the employed in relative rather than absolute terms. Assuming equal proportional returns to labour rather than an equal 'wage' (hourly or otherwise) is conceptually preferable: the CoE to GOS ratio would be the same in the employed and self-employed sectors if, hypothetically, the self-employed acted only as business owners who employed others to do the day-to-day work for them.

The model avoids the implausible result of the implied return to self-employed labour exceeding total mixed income - equation (7) shows that the weights for labour and capital in mixed income must add up to 1 . The implied returns to self-employed labour as a percentage of mixed income under this model compared to the published series and Model 1 are presented for 2000 to 2008 in Table 2, and demonstrate that only under Model 2 are the returns to self-employed labour plausible. Therefore, only under this model will the identity for calculating total income (4) hold, which is important for ensuring the consistency of productivity measures with the National Accounts. The method of estimating the labour and capital shares of mixed income is also consistent with that used in the compilation of ONS estimates of multi-factor productivity (Turvey 2009).

As with Model 1, this model addresses the key issue of differing working patterns of the employed and self-employed, although it will not specifically overcome the problem of accounting for the industries in which they work (though relative 
Table 2

Implied return to self-employed labour as a proportion of mixed income: models 1 and 2

\begin{tabular}{rrrr} 
& & Percentages \\
\hline & Published series & Model 1 & Model 2 \\
2000 & 119 & 149 & 73 \\
2001 & 117 & 147 & 74 \\
2002 & 113 & 141 & 73 \\
2003 & 119 & 149 & 72 \\
2004 & 118 & 148 & 72 \\
2005 & 118 & 149 & 72 \\
2006 & 119 & 151 & 72 \\
2007 & 120 & 147 & 71 \\
2008 & 121 & 147 & 70 \\
\hline
\end{tabular}

Source: Labour Force Survey and National Accounts, Office for National Statistics

returns to labour and capital are likely to be more similar across industries than wages). But Model 2 does tackle the issue of differing earnings of the employed and self-employed, as well as removing the problem of double-counting of HM forces and GSTs, as the measure being used to proxy self-employed labour costs (mixed income) refers only to the earnings of the self-employed.

A further advantage of this method is that all the data required to produce the series are National Statistics within the National Accounts, available on a quarterly basis in a timely fashion. In contrast, Model 1 requires hours worked data from the LFS, which would have to be extracted from LFS microdata. This would raise issues of coherence with the National Accounts data, something which also affects the current series.

Therefore, this article recommends using Model 2 to measure unit labour costs, as it represents the most credible approach to estimating the labour costs of the selfemployed, and significantly improves consistency with National Accounts data.

\section{Preliminary results}

Figures 2 and 3 show how the two proposed new models for unit labour costs would differ from the published series, in terms of indices and growth rates. Figure 2 shows a significant change in the 'headline' index series as a result of the adoption of either Model 1 or Model 2, which have actually been moving very closely to each other, especially after 2004. This is borne out by the growth rates presented in Figure 3: growth in models 1 and 2 has been very similar (with the exception of a divergence in 2003 and 2004), yet distinctly different to the published series.

The similarity between figures based on models 1 and 2, but difference of both to the published series, implies that the shift from using W\&S to CoE has a dominating impact on the results, compared to the change in estimation method for selfemployed labour costs.

In order to get a better indication of how each of the two proposed changes affects the growth rates of the published unit wage costs series, Figure $\mathbf{4}$ compares each of the changes with the published series separately for Model 2, the method recommended by this article. The 'CoE effect' shows the impact of replacing W\&S with CoE as the measure of employee labour costs while maintaining the current method of estimating labour costs of the self-employed; the 'SE effect' demonstrates how using the preferred new method of estimating self-employed labour costs but maintaining W\&S would affect growth in unit labour costs.

The chart shows a very close relationship between the 'CoE effect' line and the proposed unit labour costs series for most of the time period, indicating that the dominant force behind the differing growth rates under the proposed new methodology is the replacement of W\&S with $\mathrm{CoE}$. The change in the treatment of the self-employed has little impact on the series (apart from in 2003 and 2004), as evidenced in the close relationship between the 'SE effect' and 'published' line. Although the treatment of the self-employed under Model 2 is rather different to the current method, the 'level effect' on the series is removed by referencing to 2003 .

Therefore, the only way in which the 'SE effect' can influence the series is if growth in mixed income as a proportion of $\mathrm{CoE}$ and GOS diverges from the growth in self-employment as a proportion of total employees, something which happened in 2003 and 2004. These two years saw a large increase in self-employment relative to employment, but a much smaller differential between growth in mixed income and CoE. Table 3 shows growth rates of each of the relevant series used to proxy the self-employed for the published series and Model 2 between the first quarter of 2003 and the second quarter of 2004 .
During this period, growth in workers was far higher in the self-employed sector than in the employed sector, whereas the difference between mixed income and the sum of $\mathrm{CoE}$ and GOS was much smaller, with the latter actually growing faster in four of the six quarters. This explains the dampening effect of self-employment on Model 2, due to relatively low growth in self-employed earnings. Although not presented here, growth in hours worked by the self-employed was far higher than for employees, similar to the pattern observed for workers. The self-employed thus do not exert a downward effect on Model 1 in 2003 and 2004, which accounts for the diverging growth between models 1 and 2 seen in Figure 3.

The divergence between models 1 and 2 in 2003 and 2004 demonstrates the importance of how self-employed labour costs are measured to the overall series, which might otherwise be lost if only focusing on the most recent data given the far greater impact of measuring employee labour costs using CoE. Thus, the chosen methodology for unit labour costs should be the one which represents the most credible way of estimating the labour costs of the self employed, which this article recommends should be Model 2.

The explanation that revisions from the published series are largely driven by the move to using $\mathrm{CoE}$ to measure employee labour costs is consistent with the growth rates of CoE and W\&S presented in Figure 1: growth in unit labour costs under Model 2 tends to be higher than the published figure between 2002 and 2006, before dropping below it, and appears to be slightly less volatile over the time series.

So given the importance of differences in the growth rates of $\mathrm{CoE}$ and W\&S in determining the growth of unit labour costs relative unit wage costs, it is necessary to examine the underlying causes of these differing growth rates. Figure 5 presents growth rates of W\&S and 'social contributions' - including pension and National Insurance contributions, private health insurance and other benefits which together form $\mathrm{CoE}$, along with the proportion of CoE each accounts for. The figure shows the generally higher growth rate of social contributions relative to $\mathrm{W} \& S$, and hence shrinking proportion of $\mathrm{W} \& \mathrm{~S}$ in $\mathrm{CoE}$, which was driving the higher growth in CoE relative to W\&S between 2002 and 2006. The two largest peaks in social contributions growth, in 2003 and late 2005 to early 2006, were caused by a significant increase in National Insurance contribution rates, and large increases in employer contributions to their pension funds to meet new, tighter accounting 


\section{Figure 2}

\section{Headline unit labour costs}

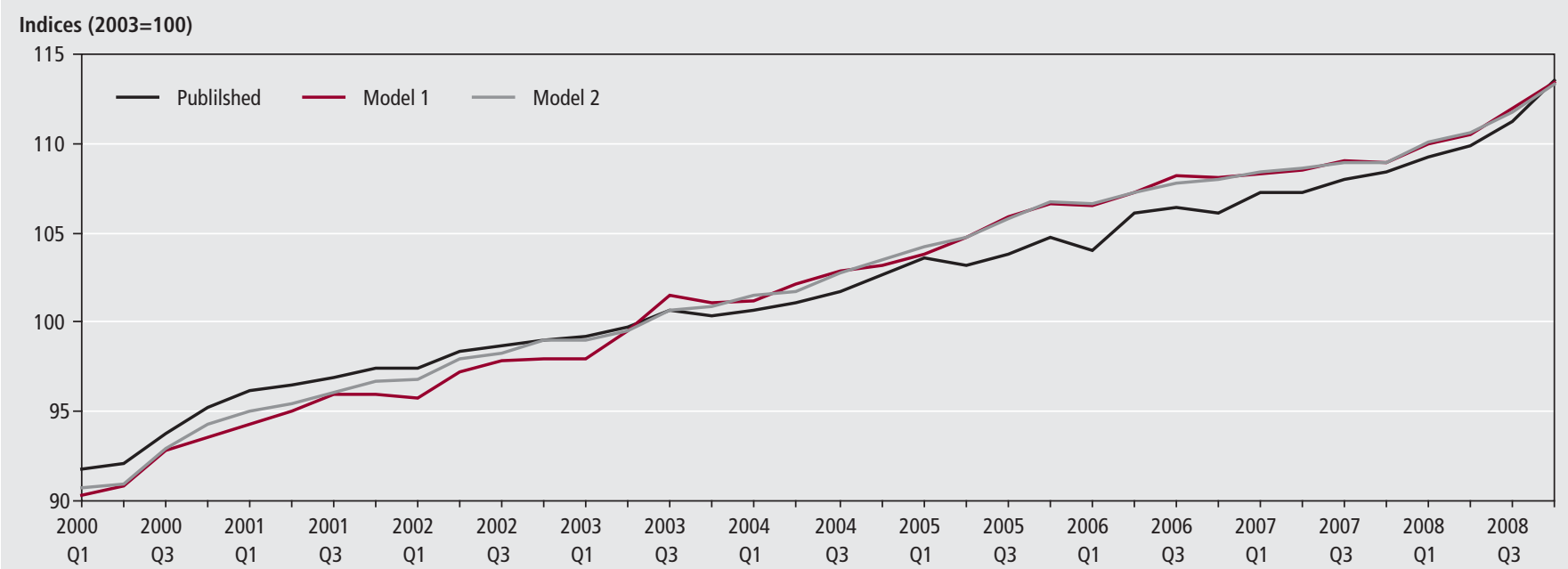

Source: Labour Force Survey and National Accounts, Office for National Statistics

Figure 3

\section{Growth in unit labour costs}

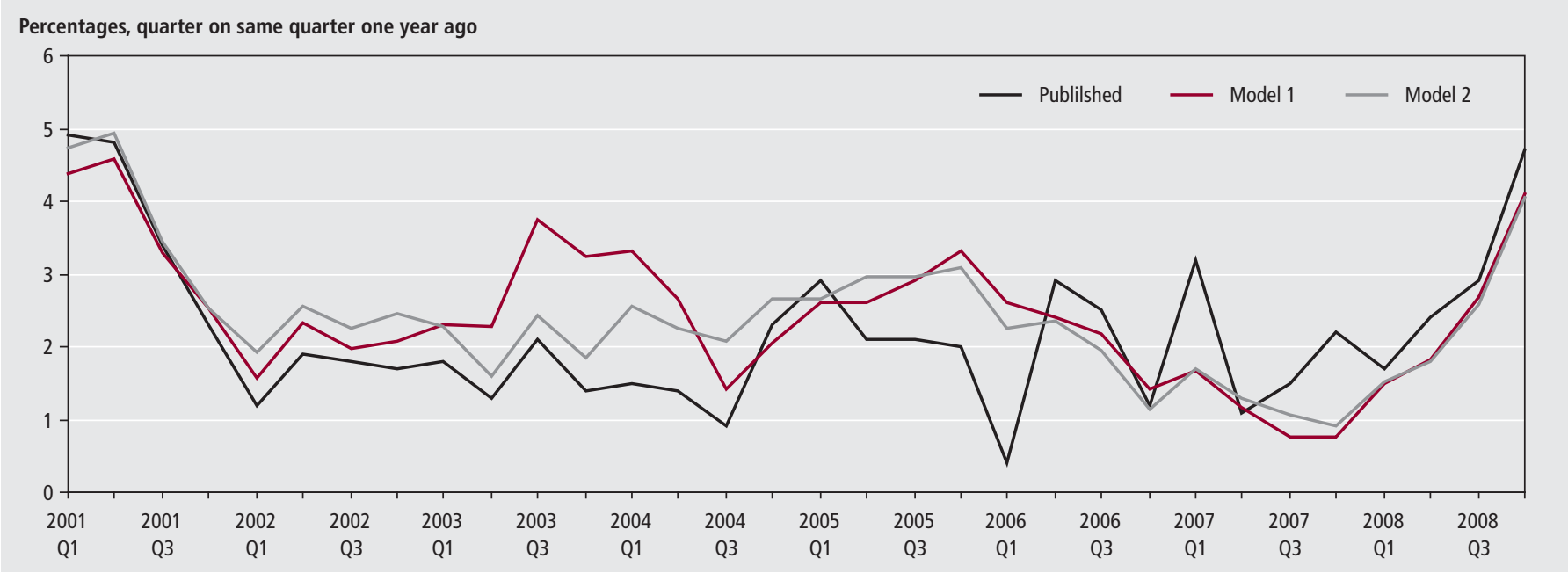

Source: Labour Force Survey and National Accounts, Office for National Statistics

\section{Figure 4}

Isolating the causes of revisions from published unit wage costs growth: Model 2

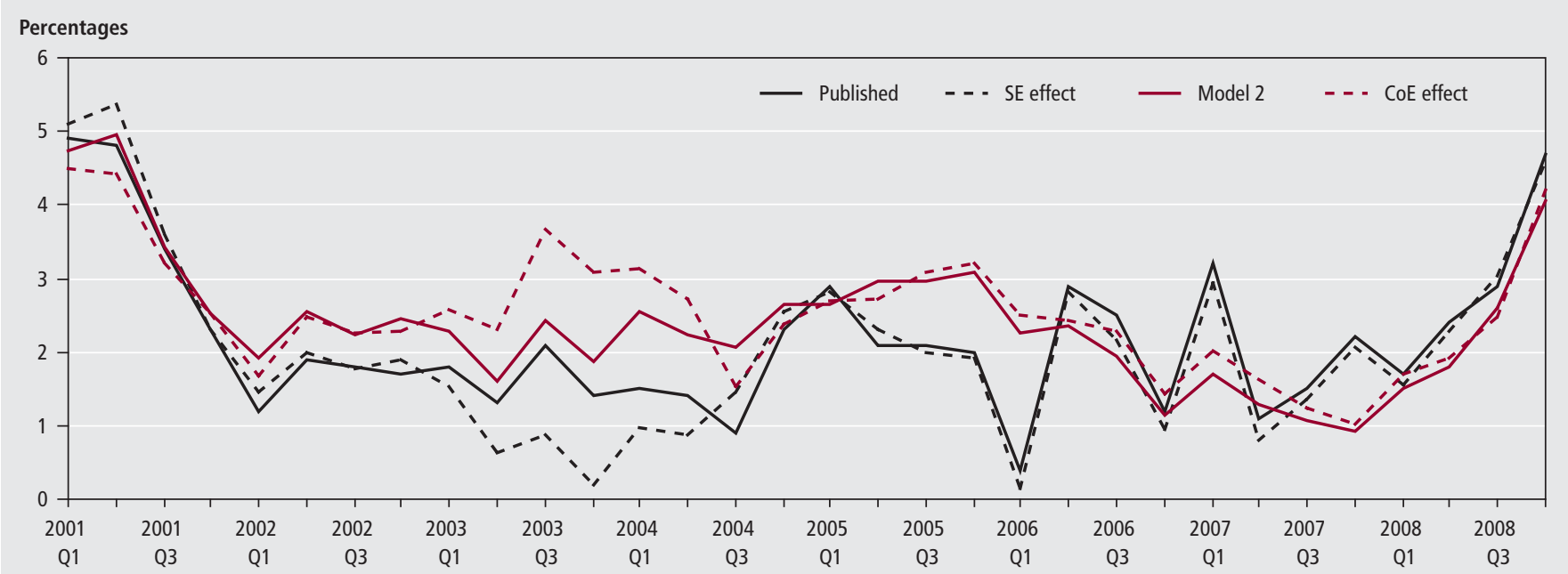

Source: Labour Force Survey and National Accounts, Office for National Statistics 
Table 3

\section{Growth in components used to estimate self-employed labour costs}

Percentages, quarter on same quarter one year ago

\begin{tabular}{|c|c|c|c|c|}
\hline & \multicolumn{2}{|c|}{ published series } & \multicolumn{2}{|c|}{ model 2} \\
\hline & total employees & self-employed & $\mathrm{CoE}+\mathrm{GOS}$ & mixed income \\
\hline 2003 Q1 & 0.9 & 3.2 & 5.6 & 3.9 \\
\hline 2003 Q2 & 0.3 & 6.6 & 6.2 & 5.8 \\
\hline 2003 Q3 & 0.0 & 8.7 & 6.2 & 5.2 \\
\hline 2003 Q4 & -0.5 & 8.8 & 6.2 & 5.7 \\
\hline 2004 Q1 & 0.5 & 5.5 & 5.0 & 7.8 \\
\hline 2004 Q2 & 0.3 & 3.3 & 5.1 & 5.7 \\
\hline
\end{tabular}

Source: Labour Force Survey and National Accounts, Office for National Statistics

\section{Figure 5 \\ Growth in wages and salaries and social contributions and their relative sizes in compensation of employees}

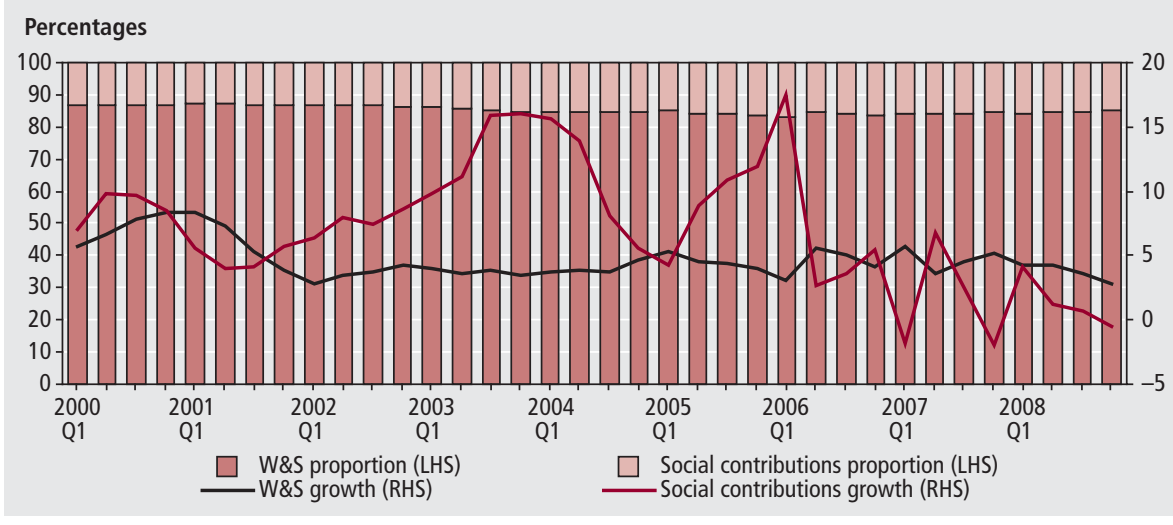

Source: National Accounts, Office for National Statistics

standards regarding their assets and liabilities, respectively. These undoubtedly represent significant labour costs to firms, and as such should be included in any unit labour costs indicator, which only strengthens the case for moving towards a CoE-based measure.

\section{Conclusion}

The two main conclusions from this analysis are:

- Compensation of employees should be considered for the calculation of unit labour costs, rather than wages and salaries, since the former includes a range of non-salary remunerations and benefits that would give a more comprehensive, coherent series

- The preferred method for estimating the returns to self-employed labour, for inclusion in the unit labour cost calculations, is to apportion mixed income to self-employed labour using the ratio of $\mathrm{CoE}$ to the sum of $\mathrm{CoE}$ and GOS in the employed sector

Although it appears from recent quarters as though the choice of Model 1 or 2 makes little difference in terms of the unit labour cost figure each yields, the two measures should only retain their close relationship as long as total hours worked by the self-employed relative to hours worked by employees and mixed income relative to the sum of $\mathrm{CoE}$ and GOS continue to grow in a similar pattern, something which did not occur in 2003-04 and it is not guaranteed to happen in future. In the event that the two measures do differ, the treatment of self-employed labour costs becomes much more important. Thus, the adoption of Model 2 is recommended by this article, as it represents the most credible proxy for the self-employed.

\section{CONTACT}

《)elmr@ons.gsi.gov.uk

\section{REFERENCES}

Lindsay C and Macaulay C (2004) Growth in self-employment in the UK, Labour Market Trends October 2004 pp 399-404 and at www.statistics.gov.uk/articles/labour_ market_trends/Growth_article.pdf

Macaulay C (2003) Changes to selfemployment in the UK: 2002 to 2003, Labour Market Trends December 2003 pp 623-628 and at

www.statistics.gov.uk/articles/labour_ market_trends/self_employment_1203.pdf OECD (2001) Measuring Productivity: OECD Manual, available at www.oecd.org/dataoecd/59/29/2352458. $p d f$

OECD (2008) Unit Labour Costs: Data and Methods, available at

http://stats.oecd.org/mei/default. asp? lang $=$ e \&subject $=19$

Office for National Statistics (2007) The ONS Productivity Handbook: A Statistical Overview and Guide, Palgrave Macmillan: Basingstoke and at

www.statistics.gov.uk/about/data/guides/ productivity/default.asp

Turvey A (2009) Multi-factor productivity: estimates for 1998 to 2007, Economic \& Labour Market Review 3(3) pp 33-38 and at www.statistics.gov.uk/cci/article. $a s p ?$ id $=2147$ 